\title{
BODY MASS INDEX AND DYSMENORRHEA IN FEMALE TEENAGERS
}

\author{
Ainun Zulkiah Surur ${ }^{1}$, Melda Putri², Asdar Fajrin Multazam³ \\ 1,2,3Program Studi Fisioterapi, Fakultas Keperawatan, Universitas Hasanuddin, Makassar \\ e-mail: andiainunzulkiah@gmail.com
}

\begin{abstract}
Introduction: Dysmenorrhea is a problem experienced by more than $50 \%$ of women in each country. This condition impacted an increase in absenteeism in school, disruption in learning activities that affects achievements in academic and nonacademic fields. One factor that is often associated with the incidence of dysmenorrhea is an abnormal body mass index (overweight and underweight). Method: This study aims to determine the relationship of body mass index and the degree of pain menstruation (dysmenorrhea) among adolescent girl in SMA Negeri 21 Makassar. A descriptive cross-sectional study was adopted in this study. Purposive sampling was used to recruit 110 respondents carried out in February-March 2019. Instrument in this study was Visual Analog Scale (VAS) to measure the degree of menstrual pain. Data analysis was performed using Chi square test and the value of $\mathrm{p}=0.00$ was obtained. Result: From this result there is a significant relationship between body mass index and degree of menstrual pain (dysmenorrhea) in young women in SMA Negeri 21 Makassar. Conclusion: Conclusions can be drawn because the value of $\mathrm{p}<0.05$ indicates that $\mathrm{HO}$ was rejected and HA was accepted.
\end{abstract}

Keywords: Adolescent, Body Mass Index, Dysmenorrhea.

\section{PENDAHULUAN}

Menurut Menteri Kesehatan Republik Indonesia (2014), remaja adalah penduduk dalam rentan usia 10 sampai 18 tahun. Pada masa remaja banyak sekali perubahan yang terjadi pada wanita, salah satunya yaitu perubahan biologis yang disebut masa pubertas dan ditandai dengan terjadinya menstruasi tiap bulan (Putro, 2017). Banyak wanita yang mengalami ketidaknyamanan fisik dan merasa tersiksa saat menjelang atau selama menstruasi berlangsung. Salah satunya yaitu terjadi nyeri haid atau dismenorea (Widyastuti et all, 2011). Lebih dari 50\% wanita di setiap negara mengalami dismenorea (Nurwana \& Fachlevy, 2016). Kejadian dismenorea menyebabkan peningkatan ketidakhadiran di sekolah, gangguan dalam kegiatan belajar mengajar, tidak memperhatikan penjelasan yang diberikan oleh guru, dan kecenderungan tidur di kelas saat kegiatan belajar yang mempengaruhi prestasi dibidang akademik maupun non akademik. Semakin berat derajat nyeri yang dialami maka aktivitas belajarnya pun semakin terganggu (Wulandari \& Woferst, 2018).

$\begin{array}{llr}\begin{array}{l}\text { Beberapa } \\ \text { dihubungkan yang }\end{array} & \begin{array}{r}\text { sering } \\ \text { dengan } \\ \text { dismenojea }\end{array} \text { antara lain usia }\end{array}$ menarche < 12 tahun, siklus menstruasi yang panjang, volume darah yang banyak saat menstruasi, merokok, riwayat keluarga dismenorea, gangguan psikologis, jarang olahraga dan indeks massa tubuh tidak normal (underweight dan overweight) memiliki kemungkinan resiko 1,2 kali lebih besar mengalami dismenorea (Nurwana \& Fachlevy, 2016). Indeks massa tubuh tidak normal (underweight dan overweight) dapat disebabkan karena perubahan pola hidup dan pola makan sebagian remaja. Pola makan tradisional mulai 
bergeser ke pola makan barat yang komposisinya tinggi kalori, lemak, karbohidrat, kolestrol, dan kurang serat seperti fast food disertai dengan peningkatan pola hidup sedentary seperti kebiasaan bermain gadget, bermain laptop yang mengakibatkan penurunan aktivitas fisik. Konsumsi makanan tinggi kalori dan lemak serta pola hidup kurang gerak (sedentary lifestyle) berkaitan dengan peningkatan prevalensi overweight. Kemudian, adanya program baru pemerintah yaitu full day school yang menyebabkan semakin padatnya kegiatan pembelajaran disekolah. menjadi salah satu pemicu terjadinya underweight (Rafiony \& Pramantara, 2015).

Menurut data Riset kesehatan dasar (2018), di Indonesia prevalensi kurus pada remaja pada usia 16-18 tahun secara Nasional sebesar 6,7\% dan prevalensi gemuk pada remaja usia 16-18 tahun sebanyak 9,5\%. Sulawesi Selatan termasuk dalam kriteria provinsi dengan prevalensi remaja overweight dan underweight cukup tinggi. Remaja dengan status gizi yang rendah (underweight) dapat mengalami anemia karena asupan makanan yang kurang, termasuk zat besi, saat seseorang anemia, dapat terjadi iskemia yang merupakan suatu keadaan kekurangan oksigen pada jaringan yang bersifat sementara. Iskemia dapat mengakibatkan dikeluarkannya fosfolipid, asam arakidonat, ion kalsium, vasopresin dan produksi prostaglandin yang berlebih, sampai akhirnya berakibat dismenorea (Ropitasari, \& Safitri, 2015).

Dalam suatu penelitian menyatakan bahwa kelebihan berat badan juga berhubungan dengan kejadian dismenorea. Hal ini dikarenakan lemak tubuh dalam jumlah lebih yang akan mengganggu metabolisme progesteron pada fase luteal dari siklus menstruasi. Akibatnya terjadi peningkatan kadar prostaglandin yang akan menyebabkan rasa nyeri pada saat menstruasi (Ropitasari, \& Safitri, 2015). Penelitian yang dilakukan oleh Wahyuni dan Oktaviani (2018) dengan judul "Hubungan Indeks Massa Tubuh dengan Dismenorea pada Remaja Putri di SMP Pekanbaru" dengan jumlah sampel sebanyak 61 orang menunjukkan hasil tidak ada hubungan antara IMT dengan kejadian dismenorea. ${ }^{10}$ Sedangkan penelitian yang dilakukan oleh Achintya (2017) dengan judul "Hubungan antara Indeks Massa Tubuh (IMT) dengan Kejadian Dismenorea Primer pada Mahasiswi Semester 7 Fakultas Kedokteran Universitas Hang Tuah Surabaya" dengan jumlah sampel sebanyak 55 orang menunjukkan hasil terdapat hubungan antara IMT dengan kejadian dismenorea. Hasil observasi yang dilakukan di SMA Negeri 21 Makassar, ditemukan sekitar 31\% siswi overweight dan $33.6 \%$ siswi underweight dari total 110 sampel pada remaja wanita usia 15-18 kelas $\mathrm{X}$ dan XI yang mengalami nyeri haid (dismenorea) dengan derajat nyeri berbeda-beda. Penelitian ini dilakukan dengan harapan agar remaja dapat memahami pentingnya upaya preventif seperti mengatur asupan gizi, dan berolahraga serta mengubah pola hidup ke arah yang lebih sehat sedini mungkin agar tubuh tetap sehat dan nyeri saat menstruasi dapat berkurang. Berdasarkan uraian di atas, Peneliti tertarik untuk meneliti lebih lanjut mengenai Hubungan Indeks Massa Tubuh dengan Derajat Nyeri Haid (Dismenorea) pada Remaja Putri di SMA Negeri 21 Makassar.

\section{METODE}

Penelitian ini dilaksanakan di SMA Negeri 21 Makassar. Lokasi dipilih mengingat jumlah siswa perempuan yang cuup banyak sekitar 789 siswi dengan indeks massa tubuh yang berbeda beda dan ditemukan sekitar $70 \%$ dari total siswi 
mengalami nyeri haid (dismenorea). Penelitian ini merupakan jenis penelitian deskriptif yang bersifat cross sectional.

Populasi dalam penelitian ini adalah semua siswi kelas X dan XI di SMA Negeri 21 Makassar. Sampel dalam penelitian ini berjumlah 110 orang purposive sampling Diperoleh dari populasi penelitian yang memenuhi kriteria inklusi yang telah ditetapkan peneliti,meliputi remaja putri kelas X-XI di SMA Negeri 21 Makassar, mengalami nyeri haid, berusia 15-18 tahun, siklus menstruasi normal 21-35 hari, dan lama menstruasi 3-7 hari.

Pengumpulan data dilakukan oleh peneliti dengan menggunakan kuesioner yang bertujuan untuk mempermudah pemilihan sampel yang memenuhi kriteria inklusi. Informasi tentang karakteristik dan keadaan umum responden, meliputi nama, umur, siklus menstruasi, lama menstruasi, riwayat nyeri haid dan keluhan saat menstruasi ditanyakan dalam kuisioner. Data berat badan, tinggi badan, dan derajat nyeri diperoleh melalui pengukuran langsung kepada responden saat berada di sekolah. Nilai Indeks Massa Tubuh diukur dengan mengambil data berat badan dengan menggunakan timbangan digital merk gea dan pengukuran tinggi badan dengan menggunakan microtoice. Nilai $z$-score IMT kemudian diinterpretasi menjadi overweight, normal dan underweight. Derajat nyeri haid diukur menggunakan Visual Analog Scale (VAS).

Data derajat nyeri haid dan indeks massa tubuh diukur menggunakan software SPSS Statistic Data Editor 22 dengan menggunakan uji chi square untuk melihat hubungan indeks massa tubuh dengan derajat nyeri haid. Hasil analisis data disajikan dalam bentuk tabel dan narasi.

\section{HASIL}

Hasil penelitian menunjukkan distribusi karakteristik responden, dari segi usia didominasi oleh siswi berusia 16 tahun sebanyak 44,5\%, siklus menstruasi didominasi oleh siswi dengan siklus 21-27 hari sebanyak 70,9\%, lama menstruasi didominasi oleh siswi dengan lama menstruasi 5-7 hari sebanyak $70 \%$ dan dari segi status ekonomi didominasi oleh siswi dengan status ekonomi sangat tinggi. Dari segi indeks massa tubuh yang dibagi menjadi 3 kategori yaitu overweight, normal dan underweight terdiri atas 34 siswi overweight, 39 siswi normal dan 37 siswi underweight. Sedangkan distribusi derajat nyeri haid dibagi menjadi nyeri ringan, sedang dan berat didomminasi oleh nyeri sedang sebanyak $74,5 \%$.

Berdasarkan analisis statistik menggunakan SPSS diperoleh nilai $\mathrm{P}$ $=0,001(\mathrm{P}<0,05)$.yang menunjukkan bahwa terdapat hubungan signifikan antara indeks massa tubuh dengan derajat nyeri haid (dismenorea).

\section{PEMBAHASAN}

Hasil penelitian ini memberikan gambaran hubungan IMT dengan derajat nyeri haid. Secara umum seseorang akan merasakan nyeri haid yang disebabkan karena rendahnya hormon progersteron dan esterogen pada akhir fase luteum, kemudian terjadi peningkatan sintesis prostaglandin dan terjadi vasokontriksi pembuluh darah arteri spiralis. ${ }^{12}$ Selanjutnya, memberikan dampak iskemik endometrium bagian kompakta dan spongiosa sehingga terjadi nekrosis. Kontraksi otot uterus yang makin kuat kemudian menjepit ujung saraf, rangsangannya dialirkan melalui serat saraf simpaticus dan para simfatikus dan dirasakanlah nyeri haid. ${ }^{12}$ Dari penelitian ini diperoleh data responden dengan IMT underweight sebanyak 37 siswi 
(33.6\%) mengalami 34 siswi mengalami nyeri sedang $(91.9 \%)$, dan 3 siswi mengalami nyeri berat $(8.1 \%)$ sehingga dapat ditarik kesimpulan bahwa rendahnya indeks massa tubuh menjadi salah satu pemicu terjadinya nyeri haid (dismenorea) sedangkan responden dengan IMT overweight sebanyak 34 siswi (31\%), 29 siswi mengalami nyeri sedang $(85.3 \%)$, dan 5 siswi mengalami nyeri berat $(14.7 \%)$ sehingga dapat disimpulkan bahwa kelebihan berat badan dapat mengakibatkan tingginya derajat nyeri haid (dismenorea) primer. Hal ini sejalan dengan penelitian yang dilakukan oleh jones 2015 mengungkapkan bahwa resiko dismenorea lebih tinggi dialami oleh remaja dengan IMT overweight dan underweight (Mundarti, Pratikto \& Triwibowo, 2014).

Terdapat perbedaan derajat nyeri pada remaja dengan indeks massa tubuh tidak normal (overweight dan underweight). Indeks massa tubuh underweight dapat diakibatkan karena asupan makanan yang kurang, termasuk zat besi yang sangat diperlukan untuk pembentukan hemoglobin $(\mathrm{Hb}) \mathrm{di}$ dalam sumsum tulang, kekurangan zat besi menyebabkan penurunan kadar zat besi plasma, sehingga suplai zat besi ke dalam sumsum tulang menjadi berkurang, sehingga hal ini menurunkan pembentukan hemoglobin dan mengakibatkan anemia yang menjadi salah satu faktor penyebab berkurangnya daya tahan tubuh terhadap rasa nyeri ketika menstruasi (dismenorea). (Hidayati, Soviana, \& Mardiyanti, 2016). Indeks massa tubuh overweight merupakan salah satu jenis inflamasi kronis tingkat rendah yang mengeluarkan prekursor prostaglandin dan menjadi salah satu faktor resiko dismenore primer (Iqlima, Wicaksono \& Effiana, 2015). Peningkatan kadar prostaglandin khususnya pada sirkulasi darah akan menyebabkan peningkatan aktivitas kontraktilitas uterus dan serabutserabut saraf terminal rangsang nyeri pada myometrium. sehingga terjadi iskemia sel miometrium dan mengakibatkan timbulnya nyeri spasmodic (Iqlima, Wicaksono \& Effiana, 2015).

\begin{tabular}{ccc}
\hline Karakteristik Responden & Frekuensi & Persentase (\%) \\
\hline Usia (Tahun) & 34 & \\
\hline 15 & 49 & 30.9 \\
16 & 25 & 44.5 \\
17 & 2 & 22.7 \\
18 & & 1.8 \\
\hline Siklus Menstruasi & 77 & 70.9 \\
21-27 hari & 32 & 29.1 \\
28-35 hari & & \\
Lama Menstruasi & 33 & 30 \\
3-5 hari & 77 & 70 \\
5-7 hari & & \\
Status Ekonomi & 51 & 46.4 \\
Sangat tinggi & 30 & 27.3 \\
Tinggi & 10 & 9.1 \\
Sedang & 15 & 13.6 \\
Rendah & 4 & 3.6 \\
Tidak menjawab & 110 & 100.0 \\
\hline
\end{tabular}

Tabel 1. Distribusi Responden Berdasarkan Karakteristik Umum Siswi 


\begin{tabular}{ccc}
\hline Karakteristik Responden & Frekuensi & Persentase (\%) \\
\hline Indeks Massa Tubuh $\left(\mathrm{kg} / \mathrm{m}^{2}\right)$ & 37 & \\
Underweight & 39 & 33.6 \\
Normal & 34 & 35.4 \\
Overweight & & 31 \\
\hline Derajat Nyeri Haid & 18 & \\
Ringan & 82 & 16.4 \\
Sedang & 10 & 74.5 \\
Berat & $\mathbf{1 1 0}$ & 9.1 \\
\hline
\end{tabular}

Tabel 2. Distribusi Responden Berdasarkan IMT Dengan Derajat Nyeri Haid ( $n=110)$

\begin{tabular}{|c|c|c|c|c|c|c|c|c|c|}
\hline \multirow{3}{*}{ IMT } & \multicolumn{6}{|c|}{ VAS } & & & \multirow{3}{*}{ Nilai $P$} \\
\hline & \multicolumn{2}{|c|}{$\begin{array}{c}\text { Nyeri } \\
\text { Ringan }\end{array}$} & \multicolumn{2}{|c|}{$\begin{array}{c}\text { Nyeri } \\
\text { Sedang }\end{array}$} & \multicolumn{2}{|c|}{$\begin{array}{l}\text { Nyeri } \\
\text { Berat }\end{array}$} & \multicolumn{2}{|c|}{ Jumlah } & \\
\hline & $\mathbf{N}$ & $\%$ & $\mathbf{N}$ & $\%$ & $\mathbf{N}$ & $\%$ & $\mathbf{N}$ & $\%$ & \\
\hline Underweight & 0 & 0 & 34 & 91.9 & 3 & 8.1 & 37 & 100 & \multirow{4}{*}{$0.000^{*}$} \\
\hline Normal & 18 & 46.2 & 19 & 48.7 & 2 & 5.1 & 39 & 100 & \\
\hline Overweight & 0 & 0 & 29 & 85.3 & 5 & 14.7 & 34 & 100 & \\
\hline Jumlah & 18 & & 82 & & 10 & & 110 & & \\
\hline
\end{tabular}

Tabel 3. Hubungan Indeks Massa Tubuh Dengan Derajat Nyeri Haid ( $n=110)$

Data pada tabel menunjukkan hasil analisis menggunakan uji chi square dan diperoleh nilai significancy $\mathrm{P}$ adalah $0,000 \quad(<0,05)$. Dapat disimpulkan bahwa terdapat hubungan antara indeks massa tubuh dengan derajat nyeri haid (dismenorea).

\section{KESIMPULAN}

Peneliti menyimpulkan bahwa terdapat hubungan signifikan antara indeks massa tubuh dengan derajat nyeri haid (dismenorea) pada remaja putri di SMA Negeri 21 Makassar. Penelitian ini diharapkan dapat menjadi sumber informasi bagi remaja agar memahami dan menerapkan pentingnya upaya preventif seperti mengatur asupan gizi, berolahraga serta mengubah pola hidup ke arah yang lebih sehat sedini mungkin agar tubuh tetap sehat serta nyeri saat menstruasi dapat berkurang. Kepada peneliti selanjutnya yang ingin menjadikan penelitian ini sebagai dasar penelitian ataupun ingin mengambil judul penelitian yang sama diharapkan dapat melakukan penelitian lebih lanjut dengan mengukur kadar prostaglandin, hemoglobin dan kolestrol responden agar hasil yang didapatkan lebih akurat. Serta dapat menambahkan variabel lain yang mungkin mempengaruhi dismenorea 
misalnya stress, cemas, anemia, dan menentukan variabel mana yang paling tinggi berpengaruh terhadap dismenorea. Serta bagi tenaga kesehatan diharapkan menjadi bahan pertimbangan dalam upaya promotif, preventif, dan penentukan program penanganan remaja dengan indeks massa tubuh tidak normal (overweight dan underweight) agar dapat mencegah dan mengurangi kasus dismenorea pada remaja.

\section{DAFTAR PUSTAKA}

Menteri Kesehatan RI. (2014). Peraturan Menteri Kesehatan RI Nomor 25 tahun. Jakarta;

Putro, K. Z. (2017). Memahami Ciri dan Tugas Perkembangan Masa Remaja. Aplikasi Ilmu,; 17: 25-32.

Widyastuti, Y., Rahmawati, A., \& Purnamaningrum, yuliasti eka. (2011). Kesehatan reproduksi (4th ed.). Yogyakarta: fitramaya.

Nurwana, Sabilu, Y., \& Fachlevy, A. F. (2016). Analisis faktor yang berhubungan dengan kejadian dismenorea pada remaja puteri di SMA Negeri 8 kendari tahun. Ilmiah, 2017; 2(6): 1-14.

Wulandari, A., Hasanah, O., \& Woferst, R. (2018). Gambaran Kejadian dan Manajemen Dismenore pada Remaja Putri di Kecamatan Lima Puluh Kota Pekanbaru,; 5 no 2: 468-476.

Rafiony, A., Purba, M., \& Pramantara, I. D. P. (2015). Konsumsi fast food dan soft drink sebagai faktor risiko obesitas pada remaja. Gizi Klinik Indonesia,; 11(04): 170-178.
Kementerian Kesehatan Republik Indonesia. (2018). Riset kesehatan dasar. Jakarta: Penelitian dan Pengembangan Kesehatan

Ropitasari, \& Safitri, I. (2015). Hubungan Anemia dengan Tingkat Dismenore. 2(36) : 1-5.

Karina, E. S., Candra, A., \& Soedarto, J. H. Hubungan Obesitas Sentral dengan Siklus Menstruasi dan Dysmenorrhea Primer pada Remaja. Journal of Nutrition College, 2017; 6(4): 319-325.

Wahyuni, R. S., \& Oktaviani, W. (2018). Hubungan indeks massa tubuh dengan dismenorea pada remaja putri di smp pekanbaru. Endurance. 3(3): 618-623.

Achintya, A. S. (2017). Hubungan Antara Indeks Massa Tubuh (IMT) Dengan Kejadian Dismenore Primer Pada Mahasiswi Semester $7 \quad$ Fakultas Kedokteran Universitas Hang Tuah Surabaya. Hang Tuah Medical Journal,; 15(1): 1-9.

Mundarti, Pratikto, J., \& Triwibowo, murdiyanto. (2014). zinc tablet administration to primer dismenore pain level,; 10(3): 856-860.

Ju, H., Jones, M., \& Mishra, G. (2013). The Prevalence and Risk Factors of Dysmenorrhea,; 36: 104-113.

Hidayati, K. R., Soviana, E., \& Mardiyanti, N. L. (2016). Hubungan Antara Asupan Kalsium Dan Asupan Zat Besi Dengan Kejadian Dismenore Pada Siswi Di Smk Batik 2 Surakarta. Kesehatan,; 1(2): 15-22.

Iqlima, A. A., Wicaksono, A., \& Effiana. (2015). Hubungan antara tebal lipatan lemak bawah kulit dan dismenore primer pada siswi sma swasta muhammadiyah 1 kota pontianak kalimantan barat,; 1-14. 